\title{
Participation and contemporary spatialities: new technologies of social agency
}

\section{SIGRADI2018 TECHNOPOLITICAS \\ xxii congresso da sociedade iberoamericana de gráfica digital 22th conference of the iberoamerican society of digital graphics 07|08|09|novembro|2018 iau usp | são carlos | sp br}

\author{
Rafael Goffinet de Almeida \\ Instituto de Arquitetura e Urbanismo | Brazil | rafael.goffinet.almeida@usp.br \\ Fábio Lopes de Souza Santos \\ Instituto de Arquitetura e Urbanismo | Brazil | sotosantos@uol.com.br
}

\begin{abstract}
Focusing on the Museu do Futebol and Google Campus - São Paulo, specifically their impacts on the space conventions of culture and labor, this article aims to investigate main questions behind the contemporary phenomena that erases previous boundaries between both fields. Manuel Castells' concept of "informational economy" will be confronted with Michel Foucault's theoretical perspective of power devices, social agency and the fabrication of the neoliberal subject to demonstrate how key terms such as participation, collaboration and interactivity - associated with informational technologies - are producing new spatialities that are functioning as sophisticated forms of social behavior and experience control.
\end{abstract}

Keywords: Participation; Contemporary spatialities; Space and Power; Social agency.

Entre 2008 e 2016, a cidade de São Paulo tornou-se sede de dois espaços inovadores (para utilizar um termo corrente) de cultura e de trabalho: o Museu do Futebol, um misto de "museu-escola" e "parque temático de aventuras", equipado com tecnologia de ponta para abordar o esporte mais popular do país como um patrimônio cultural; e o Google Campus, a versão de uma das maiores corporações de serviços online para os espaços de trabalho coletivo (coworking) e apoio para a "comunidade empreendedora" (hubs de startups). Embora representem categorias de espaços historicamente entendidas como distantes, e até mesmo antagônicas (lazer versus labor), a busca por um ambiente de descontração ou motivação capazes de promover experiências participativas, de intensa interatividade ou colaboração entre seus usuários, elementos comuns entre os discursos do Museu e do Campus, é índice de uma aproximação mais profunda do que podem aparentar. O que pretendemos investigar neste artigo são as questões subjacentes ao fenômeno contemporâneo de ofuscamento de seus antigos limites. A presença da tecnologia, a ênfase sobre a dimensão participativa de experiência social e a configuração de comportamentos inusitados através destas espacialidades compreendem, a nosso ver, os elementos de um conjunto de transformações mais amplas, ligadas à formação discursiva de um novo sujeito, em torno de uma nova racionalidade que está reorganizando as formas de nossa existência.

Para tanto, entre a presença das novas tecnologias e a formação de um nova subjetividade, confrontaremos as influentes análises de Manuel Castells sobre a "economia informacional" - marcada pelas propriedades flexíveis de comunicação, de divisão do trabalho e de gestão do processo produtivo levadas a cabo pela "revolução da tecnologia da informação" (CASTELLS, 2006) -, com a perspectiva teórica inaugurada por Michel Foucault sobre a "analítica do poder", mais precisamente a ação de "dispositivos de poder" sobre o controle dos corpos e subjetivação das mentes - ao que mais tarde incorporou à ideia de "agenciamento social" (FOUCAULT, 1994).

Embora muitas das observações de Castells sobre as características da tecnologia da informação, de uma cultura informacional a estender-se por todo o tecido social, das novas relações comunicativas por ela engendradas e de sua forma privilegiada das redes sejam caras a este estudo, não deixamos de enfrentar as razões estruturais que permitiram 0 próprio desenvolvimento tecnológico - mantidas em seu trabalho tanto mais como uma virtude das liberdades individuais. Recorrer a estas análises configura, portanto, um procedimento crítico e reflexivo, um ponto de partida para podermos avançar sobre o que, hoje, quase duas décadas após a publicação da primeira edição de "A Sociedade em Rede" (2006), devemos reconhecer como limites e contradições.

Ao enfrentamento inicial de Castells do que chamou de o "dilema do determinismo tecnológico" (2006, p.43), buscando esclarecer as relações entre tecnologia, sociedade e a economia informacional em termos de uma "conexão histórica" no desenvolvimento destas três instâncias, propomos a perspectiva foucaultiana sobre a relação entre "saber e poder" estruturando o funcionamento das instituições, o desenvolvimento de racionalidades históricas específicas e as modalidades de poder que recaem sobre os sujeitos e suas atividades (incluindo a economia e a cultura). O que nos leva a uma compreensão que acreditamos ser mais complexa sobre os objetos e fenômenos que estamos investigando, sobretudo no que podemos observar dos desdobramentos das "inovações tecnológicas", até então vistas com maior entusiasmo por Castells. ${ }^{1}$ 
Temos no horizonte o que Dardot \& Laval (2016) definiram como a fabricação do "sujeito neoliberal" (ou, "sujeito empresarial") a partir de formações discursivas específicas. Neste sentido, contrariamos Castells quando afirma que "devemos esperar o surgimento de novas formas históricas de interação, controle e transformação social", entendendo que elas acompanham pari passu o desenvolvimento das novas tecnologias. Afinal, diante de transformações evidentes sobre a condição do sujeito, objeto principal tanto para as formas e os espaços de participação geridos pelo circuito institucional da arte e cultura e pelas novas organizações empresariais, convém refletir sobre (e tensionar) tais discursos em termos da fundação de uma nova normatividade subjetiva que, se por um lado acompanha uma transformação profunda nas formas de organização social e produtiva, por outro, se concretiza através de estruturas institucionais e organizacionais como aquelas dos novos espaços de cultura e de trabalho.

Assim, nos interessa entender em um primeiro momento, os elementos, disposições e processos que cada um desses espaços informa ao outro na tarefa oculta de recodificação da experiência social em termos de participação, colaboração e interatividade. O enfoque sobre o Museu do Futebol e o Google Campus - São Paulo permitirá, em seguida, aprofundar nossas análises sobre a centralidade das novas tecnologias na construção de dispositivos para novas formas de controle do comportamento e da experiência intersubjetiva. Discussões particulares ao campo da arte e da arquitetura serão rearticuladas em categorias como saber e poder, discurso e sujeito. De acordo com Paul Hirst, outro importante interlocutor do pensamento de Foucault para este estudo, trata-se de "examinar em um novo modo a relação entre discurso e edifícios" ou, mais precisamente, "como os discursos entram em construção e como, em consequência, edifícios ou ambientes construídos se tornam afirmações [statements]" (2005, p. 156-157).

\section{INSTITUIÇÕES, ORGANIZAÇÕES E DISPOSITIVOS DE PODER}

A fim de discutir as recentes transformações na arte e na cultura, encetadas pela emergência da assim chamada "Estética Relacional", a historiadora e crítica de arte Claire Bishop, em seu influente artigo "Antagonism and Relational Aesthetics" (2004), lançou luz sobre o que identificou como uma nova tendência na produção de espaços institucionais da arte. O enfoque inicial da autora sobre o Palais de Tokyo, inaugurado em 2002, em Paris, aponta para a formação de um novo paradigma que "recontextualiza o modelo do 'cubo-branco' de apresentar a arte contemporânea como um estúdio ou 'laboratório' experimental" (BISHOP, 2004, p. 51). Termos como "obra-aberta", "participação" e "interatividade", que desde a década de 1970 já circulavam como questões-chave para diversos artistas, parecem ter finalmente encontrado um discurso curatorial e um espaço institucional adequados. Tal reorganização desponta, assim, mais que um processo de transformação interna ao circuito institucional da arte, representando um problema central que atravessa diferentes âmbitos da vida contemporânea em direção a uma nova "economia da experiência": segundo a autora, "a estratégia de mercado que procura recolocar bens e serviços enquanto experiência pessoal dirigida e encenada" (BISHOP, 2004, p. 52).

No Brasil, esta tendência se reflete na inauguração do Museu do Futebol no avesso das arquibancadas do Estádio Municipal Paulo Machado de Carvalho, o Pacaembu, patrimônio histórico da cidade de São Paulo. Reconhecido por premiações de prestígio internacional, como o Idea Awards 2010, o diálogo entre um cuidadoso projeto de intervenção arquitetônica e um ambicioso projeto curatorial almejava explorar o tema através da "ampliação de sentidos e sentimentos comuns que constituem a base da nacionalidade", conjugando as últimas tendências em expografia com a premissa de utilizar "o que há de mais novo e criativo em matéria de tecnologia (...) que emocionasse e entusiasmasse 0 público" (MUSEU DO FUTEBOL, 2016). Neste sentido, o trabalho de um conjunto de arquitetos, jornalistas, cineastas, designers e cenógrafos resultou na representação do futebol em três eixos principais "emoção", "história" e "diversão" - organizados através de um percurso espacial linear - o "Percurso do Torcedor" que conduz os visitantes às 17 salas da exposição permanente do Museu.

Atravessando os eixos temáticos, o percurso e a sequência calculada de salas (ou ambientes) de exposição, reconhecemos um denominador comum modulando a percepção dos visitantes sob a égide da experiência e da interatividade como entretenimento. Não faltam momentos que combinam, através de técnicas de design e cenografia, referências estéticas marcantes do campo das artes com a iconografia futebolística para alcançar efeitos apoteóticos e de euforia. Desde a bilheteria, localizada ao pé do Estádio, junto à praça Charles Miller, às seções "Grande Área", "Pé na bola", "Anjos Barrocos", "Rádio", "Gols”, "Espaço da Exaltação", "Origens", "Heróis", "Ritos de Passagem", "Copas", "Visita à Arquibancada", "Dança do Futebol”, “Jogo de Corpo", "Homenagem ao Pacaembu" e, já ao final do percurso, à sala "Osmar Santos", ao "Auditório Armando Nogueira" e ao conjunto de café, restaurante e loja "O Torcedor", nos deparamos com enormes planos de imagens (entre retratos, painéis, murais e projeções) e uma miscelânea de objetos, mobiliários, equipamentos e jogos desenhados para atrair nossas atenções através de sensações sonoras, visuais, táteis e das possibilidades de interação individual ou coletiva.

Entre as declarações oficiais do Museu e sua concretude física-espacial podemos identificar ao menos três questões mais significativas, a saber: a indistinção de origem entre cultura e entretenimento; a construção de uma representação cultural que reforça discursos consensuais sobre o futebol no país; e a centralidade da participação, ou envolvimento do público através de formas de comunicação midiáticas, sensoriais e afetivas. $\mathrm{O}$ que traz à tona um recorte ideológico sobre o universo de relações estabelecidas a partir do desenvolvimento do esporte.

Em "O Museu em Chuteiras: futebol, euforia e nação em espaços de imersão" (2010), Santos \& Sperling analisaram como este recorte imprime leituras restritivamente orientadas, os "discursos consensuais", como o "elogio do futebol em 'nosso' cotidiano", a "criação de 'mitos de origem' da identidade 
nacional relacionados ao futebol" e a "intensa participação" promovida pelo esporte (SANTOS \& SPERLING, 2010, p. 13). Ao recuperarem a imagem de Miguel Wisnik do futebol como uma "gangorra onipresente que balança entre o veneno da crítica ou a droga euforizante" (as cited in SANTOS \& SPERLING, 2010, p.12), os autores contrapõem à representação cultural idealizada do esporte, recobrando perspectivas mais dialéticas sobre seu entrelaçamento com a formação cultural, social e política do país. Assim como Claire Bishop sugere pensarmos em "Antagonism and Relational Aesthetics" (2004, p.79), convém observarmos "como" o observador é endereçado e também a "qualidade" da relação estabelecida entre os três eixos que compõem o protocolo de exibição do Museu do Futebol. Neste sentido, convém ainda indagarmos o quanto a linearidade do espaço museográfico e o conteúdo apresentado ao longo dele "preenche os silêncios" e "descarta qualquer possibilidade de outra articulação dos acontecimentos" (SANTOS \& SPERLING, 2010, p.12).

Neste modo específico de envolvimento do público, técnicas e discursos próprios dos meios dominantes de comunicação são combinados com fatores afetivos, especialmente através do registro histórico construído pelo Museu: figuras e acontecimentos emblemáticos do esporte se confundem com personalidades e fatos relevantes da história política e cultural do país; fotografias, imagens, filmes, além de uma série de informações foram editadas ou genuinamente cedidas por empresas de comunicação para o acervo e a montagem da exposição; pontos de vista pertencentes a outras esferas e posicionamentos sociais, políticos e culturais permanecem excluídos. O que nos coloca diante de um fenômeno contraditório e duplicado sobre a formação da memória e da identidade individual e coletiva. Afinal, se o Museu do Futebol é realmente eficaz e, portanto, reuniu conteúdo capaz de gerar identificação para o completo envolvimento do público, como podemos falar em experiência individual ao percebermos o quanto de nossa intimidade e afetividade é constantemente construída por agentes e interesses externos? $E$ trata-se de um fenômeno duplicado, pois o Museu inevitavelmente assume o papel de modelar esta subjetividade ao construir o discurso necessário para tal.

O que resta em aberto são as razões que explicam o apelo à participação, experiência e interatividade como meios de entretenimento cultural baseada nas formas, conteúdos e processos das tecnologias de informação. Curiosamente, este apelo não acontece somente no âmbito institucional, como é o caso do Museu do Futebol, mas também no âmbito das organizações representadas neste artigo pelo Google Campus - São Paulo.

Neste ponto, nos interessa a explicação de Manuel Castells sobre o surgimento das redes interativas pela integração da comunicação eletrônica. Afinal, é certo que a flexibilidade de conteúdos alcançada pelos novos meios computacionais e digitais, conforme descreve Castells, é sinônimo de uma flexibilidade das modalidades de recepção. A integração de diversas mídias comunicativas (textos, áudios e imagens) somada às possibilidades de conexão em rede (com outros meios, conteúdos e audiências) redimensionam protocolos de comportamento entre emissor e receptor em direção ao favorecimento das relações interativas entre eles e os conteúdos. $O$ jogo de Castells com os termos de Marshall McLuhan, metamorfoseando sua antiga máxima "o meio é a mensagem" em "a mensagem é o meio", traduz a sua visão de um impulso à abertura dos meios para os anseios e desejos de uma relação mais ativa com sua audiência ao fato de que, agora, "as características da mensagem [moldam] as características do meio" (2006, p.425). Trata-se, no limite, do que denominou como "cultura informacional", de modo que a amplitude da nova modalidade receptiva para diversos âmbitos da vida cotidiana, incluídos os espaços institucionais da arte e as organizações empresariais, seria, portanto, uma consequência inevitável.

Castells enfatiza que os "processos de nossa existência individual e coletiva são diretamente moldados (embora, com certeza, não determinados) pelo novo meio tecnológico" (2006, p. 108), de modo que, sob esse prisma, a dinâmica de transformação constante estabelecida entre meio e mensagem é, em última instância, o equivalente comunicacional para uma das principais leituras do autor sobre a lógica organizacional da economia informacional: o "ciclo de realimentação cumulativo entre inovação e seu uso". Como diz, "o que caracteriza a atual revolução tecnológica não é a centralidade de conhecimentos e informação, mas a aplicação desses conhecimentos e dessa informação para a geração de conhecimentos e dispositivos de processamento/comunicação da informação", de tal modo que, segue o autor, "as novas tecnologias da informação não são simplesmente ferramentas a serem aplicadas, mas processos a serem desenvolvidos" (2006, p.69).

No entanto, não encontramos nestes termos, e em nenhum outro momento de sua análise sobre a sociedade em rede, qualquer indagação sobre as consequências e os significados do novo meio tecnológico a moldar nossa existência. Para tanto, será preciso nos desvencilharmos dos conceitos de instituições e de organizações aos quais Castells se apoia para formular sua hipótese sobre a lógica organizacional. Estendendo o pensamento de Nicole Biggart, para quem enxerga nas instituições e organizações o papel de criação de "bases ideacionais para as relações das autoridades institucionalizadas" (as cited in CASTELLS, 2006, p. 209), Castells as descreve como os instrumentos de legitimação de determinada ordem, valores ou ainda de determinada racionalidade. Tanto as instituições ("organizações investidas de autoridade necessária para desempenhar tarefas específicas em nome da sociedade como um todo") quanto às organizações ("sistemas específicos de meios voltados para a execução de objetivos específicos") estariam cumprindo a tarefa de aplicar e difundir práticas, relações e discursos que, comprometidos com as mesmas expectativas e interesses por trás do desenvolvimento da tecnologia da informação, impulsionariam a formação de um "espírito do informacionalismo" (Idem, p. 209).

Por outro lado, contrariando o pensamento que enxerga as mesmas instituições e organizações como a origem para determinada organização social e de poder, Foucault reclama uma inversão do ponto a partir do qual é preciso analisá-las. ${ }^{2}$ Ao invés de debruçar-se sobre as partes e segmentações que a organizam, cada elemento, 
posição e função nela distribuída - as suas "regularidades", como prefere chamar -, interessa muito mais perceber as relações que se configuram através delas. Assim, recorreremos a três fatores presentes no pensamento de sua analítica do poder para trazermos à tona determinações políticas e sociais que se mantém obtusas sobre a "sociedade em rede": a relação entre formas de saber e formas de poder para o controle e transformação de subjetividades; o papel das instituições para a formação de instrumentos e técnicas de controle sobre o sujeito; e o desenvolvimento de "dispositivos de poder".

De acordo com Paul Hirst, desde a publicação de "As palavras e as coisas" (1966), Foucault procurou encontrar um novo entendimento sobre as condições do saber e, mais especificamente, do saber do homem sobre si mesmo. Discussões sobre a "analítica da finitude do sujeito" e o "duplo empírico-transcendental", inauguram o que em seus trabalhos mais recentes pode ser traduzido como uma complexa correspondência entre o indivíduo, a estrutura do sujeito e os discursos sobre o sujeito. Para Hirst, uma das grandes contribuições de Foucault neste percurso foi de remover 'os conceitos de 'afirmação' e 'discurso' do gueto das ideias, para demonstrar que formações discursivas devem ser consideradas como estruturas complexas de discurso-prática nas quais objetos, entidades e atividades são definidas e construídas dentro do domínio de uma formação discursiva" (2005, p.156).

Importante notar que a relação entre "estruturas de discurso-prática" e o "domínio de uma formação discursiva" envolve, no limite, a relação entre os recursos necessários a determinada forma de controle e organização social (poder) e o funcionamento efetivo de certos discursos (saber). E, nesta relação específica entre saber e poder, as instituições e organizações ocupam uma posição intermediária, fomentando saberes e constituindo relações de poder. Neste ponto, o conceito de "dispositivo" trabalhado por Foucault fornece importantes chaves de análise sobre a criação e o aperfeiçoamento de uma série de instrumentos ao longo da história ocidental capazes de envolver os homens em uma sucessão de exercícios fundamentais para, em suas próprias palavras, "detalhar ao longo de uma escala temporal o crescimento e o aperfeiçoamento da disciplina", isto é, de um desempenho social politicamente determinado (FOUCAULT, 2006, p.59). O surgimento de jogos e exercícios corporais, supervisionados por uma inteligência cada vez mais complexa de codificação, de transferência da informação para uma individualização esquemática e centralizada dos corpos e, por fim, potencializadas por uma vinculação espacial, a todos esses recursos táticos específicos de controle e dominação, Foucault deu o nome de "dispositivos de poder".

Como demonstrado em estudo anterior (ALMEIDA \& SANTOS, 2014), é possível observar o mesmo desempenho das instituições presentes nos estudos de Foucault, como a psiquiátrica, a escolar, a militar e a fabril, ocorrendo também sobre as instituições culturais. A crítica ideológica sobre os espaços expositivos de museus e galerias realizada por Brian $\mathrm{O}$ 'Doherty através de uma série de três artigos publicados no ano de 1974, demonstram como o "cubo branco", este dispositivo inaugurado pela modernidade, organizou as relações entre artista, objeto e o público, favoreceu certas produções em detrimento de outras e, dessa maneira, teve um papel decisivo para a fundação de determinadas normas e valores estéticos e de determinadas formas de subjetividade. Se naquele momento os espaços institucionais da arte e da cultura consolidaram o princípio da autonomia, da abstração e de um olhar capaz de percebê-los como a grande racionalidade da cultura ocidental, hoje este status parece ter sido deslocado para as formas de participação, de colaboração, de interatividade e de experiência institucionalmente valorizadas pela estética da obra-aberta e processual.

Resta analisarmos as condições que alçaram estes novos valores estéticos (em um primeiro momento profundamente críticos) ao status de um novo establishment cultural - em outras palavras, nas atuais "regularidades" de um conjunto de "dispositivos de poder" representado pelos novos paradigmas de espaços de arte e cultura. As três questões já aqui reunidas em relação ao Museu do Futebol, não deixam dúvidas de que o espaço privilegiado da arte e da cultura pouco mantém os traços de isolamento e distanciamento da vida cotidiana, de rigidez ou hierarquia do conteúdo selecionado para a exposição. Porém, cabe ressaltar que a institucionalização destes valores demarca um processo contraditório, ou mesmo um processo de disputa em torno dos discursos e práticas da participação desenvolvidos com maior força a partir da década de 1960. Bishop, em outro importante trabalho sob o título Participation (2006), denominou como uma "mudança de contexto" a conversão "das formas sociais", da "colaboração" e da "dimensão coletiva da experiência social" - antes uma maneira de "trazer a arte mais próxima da vida cotidiana" (BISHOP, 2006, p.10) - em promoção de eventos e ações culturais, adequados às tendências que caracterizam a organização produtiva da referida "economia da experiência" e cujos traços são, como veremos, idênticos aos da "economia informacional" de Castells.

Antes, cabe demonstrar como os termos reunidos na leitura sobre o espaço expositivo do Museu do Futebol partilham de uma mesma formação discursiva sobre a qual Pierre Dardot e Christian Laval se debruçaram em "A nova razão do mundo: ensaio sobre a sociedade neoliberal" (2016). Para os autores, as bases práticodiscursivas que caracterizam nosso momento histórico atual, por eles descritas enquanto "discurso científico" e a "história" da transformação produtiva capitalista, "registram uma mutação do discurso sobre o homem" (p. 322). Na mesma esteira de pensamento de Foucault, para quem "era preciso pensar e implantar, 'por uma estratégia sem estrategistas', os tipos de educação da mente, de controle do corpo, de organização do trabalho, moradia, descanso e lazer" (as cited in DARDOT \& LAVAL, p. 324), a ideia de uma "fabricação do sujeito neoliberal" busca articular uma transformação profunda observada nas relações sociais e de produção com a emergência de uma nova subjetividade (ou, "economia psíquica"). Trata-se de uma "nova forma de sujeição às leis impessoais e incontroláveis da valorização do capital" no mesmo momento em que observamos 0 desenvolvimento de uma nova lógica organizacional, segundo Castells, ou de uma nova "lógica geral das relações humanas" submetida à regra do "lucro máximo", 
nos termos de Dardot \& Laval (2016, p. 232-324). O mesmo movimento que instaurou a forma empresarial das redes reverbera na crítica ao neoliberalismo como uma entidade de poder, que também produziu um "sujeito empresarial" adequado às suas normas e regularidades. Em linhas gerais, esta nova estrutura subjetiva superou as regras fixas e hierarquizadas de controle para fundar o sujeito "hipermoderno", "impreciso", "flexível", "precário", "fluido", "sem gravidade" (DARDOT \& LAVAL, 2016, p. 322) de que falam os sociólogos e os psicanalistas e de cuja performance parece ser ensaiada através das formas comunicativas e de representação cultural presentes no Palais de Tokyo e no Museu de Futebol, mas que se torna ainda mais clara ao reencontrarmos disposições similares ocorrendo em espacialidades outras como é o caso do Google Campus São Paulo.

É neste ponto em que a "economia da experiência" sugerida por Claire Bishop converge com a "economia informacional" de Manuel Castells. As nomenclaturas nãos poderiam ser mais familiares, seja para descrever a esfera da cultura, o universo das novas organizações produtivas em rede ou do sujeito empresarial: organizações horizontais em substituição das antigas divisões hierárquicas; colaboração entre empregados ou equipes autônomas de trabalho; e a rede como a forma privilegiada da interatividade da economia globalizada.

Embora Castells tenha encontrado na organização da empresa californiana Cisco Systems seu maior exemplo, são as novas empresas de soluções para a internet como a Google que ocupam hoje a posição de destaque no desenvolvimento das tecnologias da informação. O que não impede de reconhecer nestas empesas os traços da "lógica organizacional" inauguradas pela primeira. Como bem descreveu Castells (2006, p. 227):

"O consenso nos círculos empresariais, inclusive a própria percepção da Cisco era que o modelo empresarial do qual foi pioneira foi o segredo de sua produtividade, lucratividade e competitividade. A Cisco aplicou a si mesma a lógica das redes que vendia a seus clientes. Organizou na Internet, e ao redor dela, todas as relações com os clientes, os fornecedores, os parceiros e os funcionários, e, por intermédio de engenharia, projetos e softwares excelentes, automatizou grande parte da interação. "

A descentralização da cadeia de produção, a grande capacidade comunicativa entre os setores autônomos de produção e a flexibilidade obtida de escala e oferta de bens e serviços inauguradas pelo "modelo Cisco" continuam sendo elementos decisivos na competitividade entre empresas baseada no "uso das tecnologias da informação para aprimorar a tecnologia da informação, na base da rede organizacional alimentada por redes de informações" (2006, p. 227).

Para além das ferramentas e soluções produzidas pela Google, grande parte das atenções atraídas pela empresa diz respeito à gestão das relações produtivas praticadas desde sua origem. A fama de um ambiente de trabalho que negou a formalidade dos escritórios das (agora já) antigas corporações, como a IBM e mesmo a Cisco Systems, se aproximando do convívio e experiência característicos do meio universitário, levou o casal de pesquisadores da Harvard Business School, Teresa Amabile e Steve Kramer a cunharem o termo "inner work of life": em suma, "as condições que promovem emoções positivas, fortes motivações internas e percepções favoráveis dos colegas e dos trabalhos em si” (2011, p.3).

Nestes termos, o Google Campus não deixa de funcionar como uma espécie de vitrine simbólica da empresa para o mercado do empreendedorismo, refletindo, por um lado, um esforço em posicionar a marca Google dentro de grandes circuitos culturais (ou simbólicos), incluindo a promoção de seus espaços de trabalho como o lugar da competitividade inovadora e criativa. ${ }^{3}$ Por outro, a criação dos campi também remete às lógicas organizacionais de que fala Castells e à institucionalização da racionalidade empresarial de Dardot \& Laval. Afinal, uma das razões que parecem sustentar este tipo de investimento pode ser atrelada, primeiramente, ao impacto que esta nova organização produtiva incide sobre o referido conceito do "ciclo virtuoso da revolução da tecnologia da informação". Não por menos, o espaço reservado às atividades de startups residentes, selecionadas pela empresa através de editais próprios, ocupa metade de todo o edifício do Campus São Paulo, além de despontar como a principal atividade na grade de programação de todo o conjunto. $O$ fato de atrair para si empresas e empreendedores com potencial de inovação tecnológica, fornecendo suporte não apenas em infraestrutura e espaço físico, como também de consultores da própria empresa, a Google encontrou uma maneira singular de participar ativamente

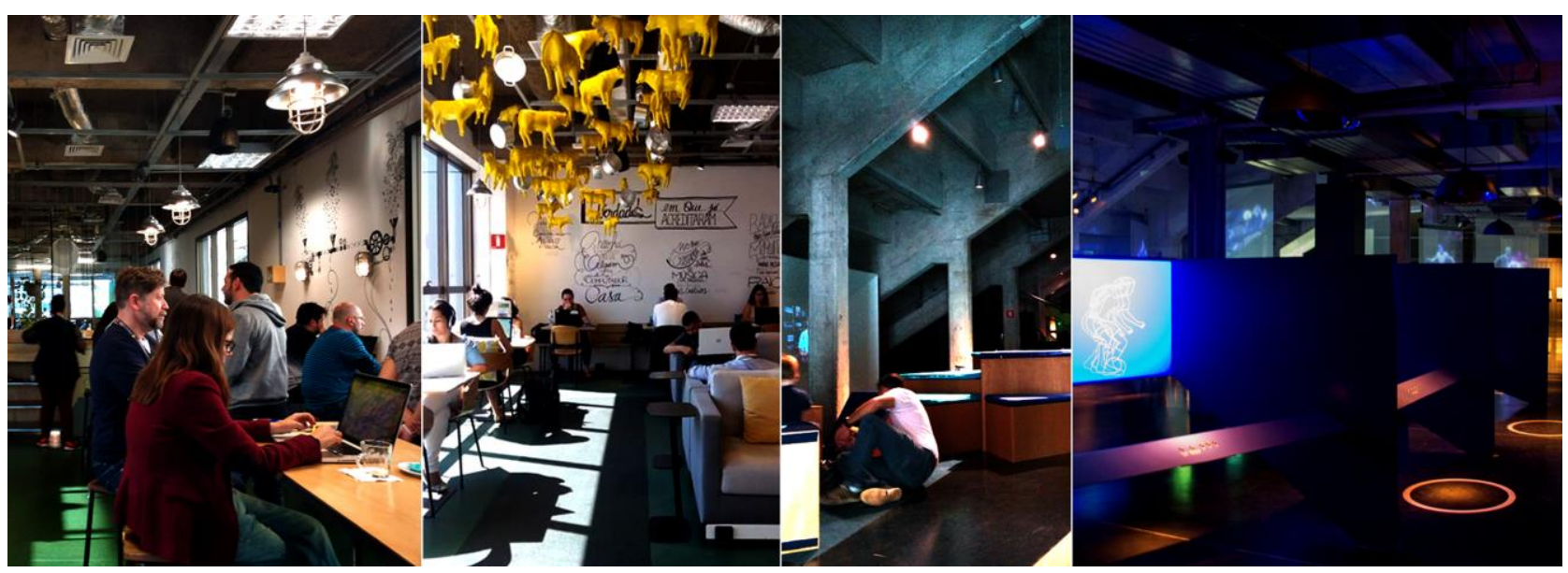

Figura 1: cenas do Google Campus São Paulo (à esq.) e do Museu do Futebol (à dir.). Fonte: Autores. 
do ciclo identificado por Castells. Como uma espécie de expansão dos setores de P\&D, comum em qualquer organização do ramo, a Google fomenta e difunde seus produtos e serviços de tecnologia da informação ao incorporar empreendimentos diversos, organizando, de acordo com seus próprios interesses, pesquisas e desenvolvimentos que se encontram dispersos no universo do empreendedorismo. ${ }^{4}$

No entanto, quando Castells critica as trajetórias organizacionais da década de 1980, que precederam o surgimento do "modelo Cisco", argumentando que o uso de novas tecnologias apenas funcionavam como um "dispositivo para economizar mão-de-obra e oportunidade de controlar os trabalhadores e não um instrumento de transformação organizacional” (2006, pp. 229-230), notamos que autor evita reconhecer neste modelo o desenho de novas formas de controle, que se tornam ainda mais sofisticas naquelas ensaiadas através da espacialidade do Google Campus. Desta perspectiva, estes verdadeiros dispositivos espaciais funcionam tanto como um convite ao público empreendedor para experimentar a "cultura" produtiva promovida pela empresa, inserindo-se de maneira mais incisiva (concreta e simbolicamente) nos principais centros econômicos globais, quanto a criação de um ambiente onde se pode ensaiar novas formas organizacionais para novas formas de produção e de relações de trabalho.

Acompanhando, então, o que Castells chamaria de "cultura informacional" dos espaços de trabalho coletivos, a Google inaugurou em Londres, no ano de 2011, o primeiro de seus 8 campi espalhados pelo mundo: os "espaços Google para empreendedores", como informa o website da empresa, lugares "de encontro para pessoas inovadoras compartilharem ideias, aprenderem umas com as outras e apoiarem o ecossistema local" (GOOGLE, n.d.). Cinco anos depois, o Brasil se tornou a sede do segundo maior campus e o único das Américas. Localizada próximo ao centro financeiro e cultural da Av. Paulista, a empresa reformou um edifício corporativo de 6 andares para fornecer, além dos quatro pisos exclusivos para o projeto de residência, um conjunto aberto à utilização do público empreendedor em geral (o "Campus Café"), inclusive para propostas de atividades diversas ligadas ao universo do empreendedorismo (como workshops, palestras, encontros, treinamentos ou sessões de yoga).

Em comum entre os campi, destaca-se um projeto de customização dos espaços, cujo apelo visual e sensorial se aproxima do mesmo espaço-cenográfico que caracteriza o projeto curatorial do Museu do Futebol. Embora não apresente os mesmos recursos tecnológicos, a conformação de um inner work life positivo entre os empreendedores visitantes ou residentes parece depender de um ambiente que estimule ou favoreça a interatividade e a sensação do trabalho menos como labor, pois criativo.

Nos referimos ao projeto de reforma para a instalação do Campus - São Paulo como um projeto de customização devido à importância dos mobiliários, de boa parte dos objetos decorativos, dos materiais de acabamento e da comunicação visual como elementos estruturantes para a organização do espaço e de sua experiência social. Contudo, três características ou funcionalidades se destacam: a segmentação de cada andar em unidades de ambiente bem definidas, embora espacialmente integradas (com exceção das varandas, sempre isoladas por amplas portas de correr envidraçadas); a prescrição de usos, condutas ou comportamentos; e a equalização de atmosferas de animação social, de acordo com as expectativas de cada unidade ambiental.

O cenário de fundo onde variam murais, pinturas de parede e mobiliários de diferentes formas e tamanhos remete a uma identidade típica dos laboratórios e fábricas de criação: o forro foi dispensado, mantendo aparentes as vigas que cruzam os pilares e parte das instalações elétricas, hidráulicas e de ar-condicionado. A alusão aos lofts convertidos em espaços de trabalho de uma geração de artistas do SoHo da década de 1970, à semelhança do que relata Bishop em "Relational Aesthetics and Antagonism", não é mera preferência estilística. O mesmo pode ser dito ao predomínio de ícones e símbolos da cultura urbana, como os enormes grafites ou as cabines telefônicas convertidas em estúdios individuais ou balanços suspensos (na versão dos antigos "orelhões" de Chu Ming Silveira). Afinal, desde os primeiros contornos do que hoje denomina-se como "economia criativa", a cidade tem sido tomada como lugar e imaginário férteis para a conversão da multiplicidade, da diversidade, da diferença e da inovação como capital cultural e simbólico (YÚDICE, 2004).

De fato, parece ter sido grande a preocupação da empresa em oferecer a seu público diferentes "estados" de animosidade no dia-a-dia de trabalho dentro do campus. É possível transitar com facilidade de uma espécie de lounge, aconchegante e descontraído pelo tom avermelhado e escuro das paredes, pelas mesas de bilhar à disposição e por um corredor formado por futons de uso coletivo, ocupando metade do 50 andar, para a "área de silêncio", localizada após a escadaria, que funciona como uma espécie de pátio interno de conexão com o andar superior. Se no meio do caminho resolver "experimentar" um café antes de concentrar-se no trabalho, subindo e saindo logo à esquerda, chega-se à área de encontros, amparado pelo "Projeto Fazedores de Café" - e não se preocupe, na volta, um rebanho de vacas amarelas suspensas quase à altura da cabeça não deixarão esquecer que estará entrando em um lugar de muito trabalho e pouca conversa.

Diferente do Museu do Futebol, o Google Campus não se destaca pela variedade espetacular de dispositivos de tecnologia de informação. Aliás, espera-se que o empreendedor tenha seu próprio instrumento de trabalho. Designers, arquitetos, programadores, freelancers de qualquer modalidade ensaiam formas diversas de lidar com seus gadgets a partir da miríade de mobiliários existentes por todos os ambientes: mesas para quatro pessoas, bancadas coletivas altas e baixas, mesas individuais, sofás, poltronas, futons, cabines telefônicas para quem precisa de isolamento acústico, etc. As varandas são para momentos ao ar livre, portanto, nada melhor que espreguiçadeiras e cadeiras de praia rodeadas por um paisagismo de apartamento.

Contraditoriamente, são estes mesmos elementos responsáveis por definir os limites da participação no campus. Não foi reservada, nem enquanto a animosidade de um ambiente específico, a possibilidade dos usuários 
organizarem o espaço de trabalho por si próprios. Por mais dinâmica, descontraída e motivacional com que se pareça, e por mais distante que se apresente da linguagem arquitetônica funcionalista (marcada pela racionalidade objetiva da padronização e distribuição setorizada de funcionários e suas atividades através dos pavimentos-tipo dos edifícios corporativos, como aqueles projetados por Mies van der Rohe, ícone da arquitetura modernista da década de 1950), ainda assim, o projeto de customização reflete uma natureza rígida, avessa aos valores estéticos de flexibilidade e não-autoria da "obraaberta". Também não são poucas as advertências de uso distribuídas pelos ambientes, deixando mais explícitas o caráter comum de manual ou políticas de comportamento que parece dominar todo o espaço. ${ }^{5}$

Se as práticas engendradas no interior do Google Campus pouco exploram a dimensão de autonomia que deveria acompanhar o apelo à participação e relações não-hierárquicas de trabalho, convém indagarmos os efeitos gerados sobre a experiência social destes usuários.

Parte deste fenômeno reflete uma história social de transformação das revoltas imateriais, que marcaram a busca por maior autonomia durante as décadas de 196070 , em novas formas de controle produtivo e social em tempos mais recentes, como apontam os estudos de Eve Chiapello e Luc Boltanski em "O Novo Espírito do Capitalismo" (2008). Nele, os autores demonstram como o capitalismo avançado, baseado na economia financeira e de serviços, transformou as críticas sociais e estéticas feitas ao modelo de produção industrial vigentes durante o Pós-Guerras em novos modelos de gestão empresarial, sobretudo a partir dos anos 1990. À semelhança do que pudemos observar em relação à busca por outras relações entre a arte e as regularidades do espaço expositivo, as décadas que sucederam a implantação e o aprimoramento da linha de montagem nas fábricas, bem como o tipo de organização produtiva e também social que dela se derivou, resultou em uma insatisfação traduzida não somente na reivindicação por melhores condições econômicas (aumento de salários, redução da jornada de trabalho, garantias diversas), como também gerou um novo tipo de demanda: contrariando formas mecanizadas, tecnicizadas e tecnocráticas de trabalho e de vida social, emerge a defesa pela "capacidade criativa do homem e sua autonomia" (CHIAPELLO \& BOLTANSKI, 2009, p.208).

Nesse momento de "crise do trabalho", dizem os autores, "o capitalismo foi obrigado a propor formas de engajamento compatíveis com o estado do mundo social no qual está incorporado e com as aspirações de seus membros que conseguiram expressar-se com maior força" (Idem, p.208). O controle produtivo baseado em sistemas de "punições-recompensas", que ainda perduravam nos anos 1960, deu lugar a uma "apologia da mudança, do risco e da mobilidade", traduzindo os anseios por criatividade e autonomia em uma aparente sensação de liberdade, liderança, compartilhamento e autorrealização" (Idem, pp.122-123).

Contudo, resta latente um segundo e decisivo campo de investigação: a emergência de uma nova norma subjetiva para as relações de poder que se inauguraram a partir deste quadro histórico de reorganização produtiva. Nos interessa olhar com atenção para o que Dardot \& Laval definiram como a formação de um "sujeito ativo", a fundação de uma ética da "autovalorização" pelo neoliberalismo e que possui, enquanto suas "asceses", determinadas "técnicas de comunicação".

Em primeiro lugar, os autores demonstram como as reivindicações por maior liberdade e autonomia se converteram em uma forma sofisticada de controle e dominação das relações sociais e de trabalho. A disputa gerada a partir da reorganização produtiva, não mais pautada pelos rígidos valores de hierarquia e distribuição de funções, redimensionou o posicionamento do sujeito. No interior de uma estrutura prático-discursiva flexível, mas que responde ao imperativo da reprodução capitalista, as esferas da vida pessoal e profissional se confundem. Aparentemente livre dos antigos instrumentos de subordinação, é o próprio sujeito quem deve garantir a eficácia de seu desempenho. Afinal, tratase, agora, "de ver nele o sujeito ativo que deve participar inteiramente, engajar-se plenamente, entregar-se por completo à sua atividade profissional" (DARDOT \& LAVAL, 2016, p.327).

A participação é traduzida, nestes termos, enquanto um imperativo de poder, um controle sistemático de si mesmo, de modo que o desejo de participação do sujeito é fundamentalmente uma forma de desejo alheio. Valores antes aplicáveis apenas às entidades empresariais e corporativas fazem parte das relações sociais do "sujeito empresarial". Competitivo, espera-se que o indivíduo desenvolva "atitude social", no sentido de explorar a autonomia recém conquistada para a sua "autovalorização" no mercado (Idem, p.337). É como se um fio de Ariadne rearticulasse todas estas formas em razão de um propósito omisso - ou, como Foucault antecipava, uma evidência oculta e diferente às relações e formas mais aparentes. No lugar de orquestrar uma dinâmica social efetivamente autônoma e constituída por práticas sociais conscientemente libertadoras, o reposicionamento do indivíduo enquanto elemento central nas relações sociais e produtivas são antes encetadas por um processo de subjetivação que o subordina de uma maneira inédita a uma totalidade e, portanto, a uma ordem exterior: a da empresa neoliberal.

Devemos nos perguntar, ainda, sobre as condições para o desenvolvimento deste ethos do "empresário de si mesmo" e quais seriam estes instrumentos para o aperfeiçoamento de seu exercício, para um processo específico de subjetivação. É desta perspectiva que entendemos a emergência de técnicas de "gestão do euempresa", identificadas como as formas de "controle e avaliação de personalidade", de "maneiras de ser, falar e mover-se", de "motivações inconscientes" (Idem, p.340). Entre elas, despontam as técnicas de comunicação, capazes de garantir maiores desempenhos de um indivíduo na competição com os outros.

A referida integração da comunicação eletrônica e as novas disposições entre meios e mensagens, descrita por Castells, refletem aqui a origem das formas mais sofisticadas de envolvimento do público: a busca por entender como nos comunicamos, os estados do "eu", a formulação de jogos sociais que estimulem o controle da comunicação e um certo estado de sincronização com os interlocutores. Orientados pela lógica de "acompanhar e

7 
conduzir", as técnicas de comunicação constituem os instrumentos necessários para se estabelecer, por exemplo, o grau necessário de identificação e empatia para a conquista do "sujeito ativo", para obter deste "colaborador" (agora "aberto", "síncrono", "positivo", "empático", "cooperativo") "o desempenho que se espera dele" (Idem, pp.340-344).

\section{ESPACIALIDADES EMERGENTES: CONCRETIZAÇÃO DO DISCURSO NEOLIBERAL}

A eficácia do dispositivo construído pelo Museu do Futebol e pelo Google Campus pode ser medido, portanto, pela satisfação proporcionada ao público pela série de experiências, emoções, sensações e motivações. Mas devemos indagar também o caráter, a qualidade ou as propriedades que especificam esta satisfação. Uma primeira constatação nos leva à sentença de que maiores sucessos terão estes espaços se conseguirem estabelecer uma relação de profunda proximidade em relação às expectativas de seu público. Não por menos, pudemos ver como a forma da comunicação corporativa adotada pela curadoria do Museu, quanto as formas próprias da cultura presentes no Google Campus buscam construir pontos de aderência para o maior envolvimento possível de cada visitante com o discurso espacializado através do percurso de visitação ou através das segmentações de ambientes customizados. À medida que o visitante avança percurso adentro, ou a cada tempo aproveitado de trabalho, este incorpora as regras que definem a narrativa-experiência, como se sua participação-interação fosse menos a resposta esperada pelo projeto curatorial e de customização do que seu próprio desejo de responder às informações com que se depara.

Nota-se, por fim, que muitos dos recursos explorados por estas modalidades de representação cultural e de gestão do trabalho se estendem para e se confundem em tantas outras categorias de espaço. Estamos diante de um fenômeno amplo em que soluções arquitetônicas, culturais e de tecnologias de comunicação/informação constituem um partido de organização de nossas formas de existência: a emergência de novas espacialidades concretiza os discursos de uma nova modalidade de poder. Pensemos, ainda, na importância que o fator afetivo possui na construção de ambientes de moradia, lazer, esporte comércio ou mesmo os espaços públicos, como os atuais produtos do mercado imobiliário sob a insígnia das smart houses, o arrendamento de imóveis via Air $B n B$, os clubes-cafés e as lojas-conceitos oferecendo serviços (ou experiências) exclusivos a seus clientes, a customização dos espaços públicos através da instalação de parklets ou de pocket parks. Impossível não reconhecer através destes exemplos o dispositivo cenográfico-espacial atuando como um "laboratório de experiência", não exatamente como aquele a que se referiu Claire Bishop sobre o Palais de Tokyo, mas como o "dispositivo de poder" de Foucault, fomentando saberes na forma de sistemas e métodos para atingir um grau de envolvimento do sujeito que só encontra paralelo nas observações sobre a ética da autorrealização.

\section{NOTAS}

1. Esta percepção ecoa o que David Harvey identificou como sendo o "interesse do neoliberalismo pelas tecnologias de informação e a sua promoção dessas tecnologias". Ver: HARVEY, D. (2014). O Neoliberalismo: história e implicações. São Paulo: Edições Loyola. p.13.

2. Castells cita Foucault para questionar sua ideia de uma "microfísica do poder" encerrando "os sujeitos em uma estrutura rigorosa de deveres formais e agressões informais", preferindo, no lugar, um conceito de poder baseado no "estado e seu monopólio institucionalizado da violência" (CASTELLS, 2000, p.52).

3. O lançamento do longa "The internship" (2013), estrelado por dois renomados comediantes de Hollywood, Owen Wilson e Vince Vaughn, é o exemplo mais caricato.

4. Até o momento da pesquisa, não foi possível obter informações precisas sobre o tipo de relação contratual entre a empresa Google e os residentes por ela selecionados. De modo que, o domínio da primeira sobre o trabalho produzido (a "inovação") pelas equipes pode ser inferido a partir de análises mais amplas sobre o conceito de "economia criativa" (correlata à economia informacional originalmente cunhada por Castells), como é o caso da função política da "propriedade intelectual". Segundo George Yúdice, a regra geral para indústrias baseadas em "direitos de propriedade" é a obtenção do lucro por possessão, quando "os que não têm esses direitos ou os que perderam por aplicação de leis concebidas para favorecer os interesses das corporações são relegados ao trabalho de provedores de serviço e conteúdo" (YúdICE, 2004, p.37).

5. Relato de uma frequentadora dos espaços de coworking resumiu o sentido coletivo do termo na versão do Google Campus aos murais de anúncio de empregos, e criticou a presença de equipes terceirizadas de limpeza e de serviços de café, comprometendo relações genuínas de cooperação e pertencimento entre os empreendedores ao isentá-los das atividades de manutenção e tomadas de decisão sobre o espaço. Ver: HADDAD, A. (2016). O que há de bom e o que falta ao Google Campus, em São Paulo, que já é uma referência para empreendedores. Retrieved from https://projetodraft.com/o-queha-de-bom-e-o-que-falta-ao-google-campus-em-sao-paulo-queja-e-uma-referencia-para-empreendedores/.

\section{REFERÊNCIAS}

ALMEIDA \& SANTOS. (2014). Dan Graham e a Cidade Contemporânea: dispositivos espaciais, comportamento e relações de poder. Anais do XVIII Congreso del SiGRADI. 1 (8), 505-508.

AMABILE \& KRAMER. (2011). The Progress Principle: using small wins to ignite joy, engagement and creativity at work. Boston: Harvard Business Review Press.

BISHOP, C. (Fall 2004). Antagonism and Relational Aesthetics. October, 110, 51-79.

BISHOP, C. (2006). Participation: Documents of Contemporary Arts. London/Cambridge: Whitechapel Ventures/The MIT Press.

BOLTANSKI \& CHIAPELLO. (2009). O novo espírito do capitalismo. São Paulo: Martins Fontes.

CASTELLS, M. (2006). A Sociedade em Rede. São Paulo: Paz e Terra.

DARDOT \& LAVAL. (2016). A nova razão do mundo. São Paulo: Boitempo.

FOUCAULT, M. (1994). Dits et Escrit. Paris: Gallimard.

FOUCAULT, M. (2006). O poder psiquiátrico: curso dado no College de France (1973-1974). São Paulo: Martins Fontes. 
FOUCAULT, M. (2016). As palavras e as coisas: uma arqueologia das ciências humanas. São Paulo: Martins Fontes.

GOOGLE. (n.d.). Campus Startup Report. Retrieved from https://www.campus.co/sao-paulo/pt/about/

HIRST, P. (2015). Space and Power: Politics, War and Architecture. Cambridge: Polity Press, 2015.

Museu do Futebol. (2016). Retrieved from http://www.museudofutebol.org.br
O'DOHERTY, B. (2002). No interior do Cubo Branco: a ideologia do espaço da arte. São Pauo: Martins Fontes.

SANTOS \& SPERLING. O Museu em chuteiras: futebol, euphoria e nação em espaços de imersão. Anais do 20 Seminário Internacional Museografia e Arquitetura de Museus, Rio de Janeiro: FAU/PROARQ, 01-19.

YÚDICE, G. (2004). El Recuerso de la Cultura: usos de la cultura en la era global. Barcelona: Gedisa. 